\title{
A Study to Analyse Correlation of Plate Position with Flexor Pollicis Longus Tendon Attrition in Patients Managed With Volar Plating
}

\author{
Amit supe ${ }^{1}$, Jayesh Anant Mhatre ${ }^{2 *}$, Kartik Pande ${ }^{3}$, Niraj Tiwari ${ }^{4}$ \\ Department of Orthopaedics, Grant Government Medical College, Mumbai, Maharashtra, India
}

Corresponding Author: Jayesh Anant Mhatre, Department of Orthopaedics, Grant Government Medical College, Mumbai, Maharashtra, India.

Received Date: December 15, 2021; Accepted Date: December 31, 2021; Published Date: January 11, 2021

Citation: Amit Supe, Jayesh Anant Mhatre, Kartik Pande, Niraj Tiwari (2022). A Study To Analyse Correlation Of Plate Position With Flexor Pollicis Longus Tendon Attrition In Patients Managed With Volar Plating. J. Clinical Orthopedics and Trauma Care, 4(1); DOI:10.31579/26940248/025

Copyright: () 2022 Jayesh Anant Mhatre, This is an open access article distributed under the Creative Commons Attribution License, which permits unrestricted use, distribution, and reproduction in any medium, provided the original work is properly cited.

\begin{abstract}
Background: Purpose of this study was to study association of flexor pollicis longus tendon (FPL) attrition using Ultrasonography with plate position on radiographs in patients managed with volar locked compression plate fixation (LCP) in distal radius fractures.

Methods: Status of flexor pollicis longus tendon was analysed by ultrasonography in patients who underwent volar locked compression plating a minimum of one year follow up. Soong's criteria were used to assess the plate position and then correlated with the ultrasonography findings of flexor pollicis longus.

Results: There were 45 patients included in our study, of which 28 belonged to Soong's grade zero, 10 were grades one and 7 were grade two. Flexor pollicis longus attrition was noted in 5 cases with grade two plating.
\end{abstract}

Conclusion: Amongst the cases with grade 2 of Soong's criteria, attritional changes were seen in 72 percent of patients , which warrants a proper follow up to identify any impending signs of tendon rupture and to make early intervention to prevent rupture.

Keywords: distal radius fracture; flexor pollicis longus tendon attrition; attritional changes; plate position

\section{Introduction}

Distal end radius fractures are one of the commonest fractures treated by surgeons and accounts for $2.5 \%$ of all cases presenting at the emergency room [1]. Treatment options for these fractures range from conservative management with cast, percutaneous $\mathrm{k}$ wire fixation, external fixator and open reduction and internal fixation with various of plates available [2]. The appropriate treatment depends on fracture patterns with associated soft tissue condition, age other variables like fracture comminution, pattern, and displacement type [3]. The volar locked compression plate (LCP) has gained popularity in the recently and is used in commonly among of the fracture pattern. This method enables good functional results with better fragment stability and lesser complication rates and early mobilisation when compared to other procedures. Sometimes the volar locked compression plating maybe associated with complications like infection, stiffness and rarely tendon ruptures or attrition due to very distal plate position which may irritate these tendons $[4,5]$.
Among these complications, rupture of the flexor is a rare but serious complication. The flexor pollicis longus (FPL) is the most frequently ruptured tendon, followed by the index flexor digitorum profundus. Symptoms and signs of FPL attrition or rupture include pain and a rubbing sensation with movement, sometimes preceded by volar radial-sided wrist pain, volar wrist swelling, a popping or clicking sensation, and even an inability to flex the interphalangeal joint of the affected phalanx [6, 7]. In view of the above problems, we should strive to identify the risk factors for tendon attrition or rupture and to intervene accordingly. The pathogenesis of FPL attrition or rupture after volar plating of distal radius fractures is multifactorial [8]. Reported risk factors include excessive distal placement of the plate, increased prominence of the distal edge of the plate, prominent screw heads, inbuilt malreduction, and incorrect plate usage. However, no studies have included the use of multiple regression analysis to explore the aforementioned possible factors $[9,10]$. In the present study, binomial analysis combined with multivariate logistic regression analysis was performed to investigate the risk factors associated with FPL attrition or rupture. Based on previous studies by 
J. Clinical Orthopedics and Trauma Care

other research groups, we hypothesized that the type of plate used, the fracture reduction status, the plate position, whether the pronator quadratus is repaired, and the time of plate removal are significant risk factors associated with FPL attrition or rupture. The flexor tendon attrition and ruptures appear to be related to inappropriate plate position, where crossing the water shed line may increase the possibility of tendon irritation [11]. This study was undertaken to look for flexor pollicis longus (FPL) tendon attrition or rupture by ultrasonography (USG) and correlate the same with radiographs for plate position following volar locked compression plating in patients who had undergone PQ repair for distal radius fractures. We also noted the status of PQ repair. The objective was to know whether the information provided by the USG would be useful to a surgeon for deciding early plate removal.

\section{Materials and Methods}

We retrospectively reviewed the records of 45 consecutive patients who had underwent surgical repair involving volar plating from January 2020 to June 2021 at our hospital. Informed consent was explained and then obtained from all patients before the operation. The inclusion criteria were

\begin{tabular}{|l|l|l|}
\hline Age group & Males & Females \\
\hline $\mathbf{2 1 - 3 0}$ & 5 & 2 \\
\hline $\mathbf{3 1 - 4 0}$ & 8 & 6 \\
\hline $\mathbf{4 1 - 5 0}$ & 5 & 4 \\
\hline $\mathbf{5 1 - 6 0}$ & 4 & 3 \\
\hline $\mathbf{6 1 - 7 0}$ & 5 & 5 \\
\hline Total & 25 & 20 \\
\hline
\end{tabular}

All patients were regularly followed up at 6 weeks, 3 months, 6 months and up to a period of minimum of one year after the distal radius fracture fixation and observed for fracture healing and clinical improvement (1236 months with mean follow up of 18 months). At the end of one year follow up, standard posterior-anterior and lateral radiographs were taken to assess the plate position according to the Soong's criteria [12, 13]. The true lateral radiograph was taken with forearm in midprone position and wrist in neutral position such that on drawing a straight line, axes of radius, lunate, capitate and third metacarpal all are in same line or within 10 degrees coaxial. On a true lateral radiograph of wrist, a "critical line" was drawn tangential to the most volar extent of the volar rim, parallel to the volar cortical bone of the radial shaft. Plates that did not extend volar to the critical line were recorded as Grade 0 . Plates volar to the line but proximal to the rim (such that the recess of the pronator fossa could be clearly visualized) were recorded as Grade 1. Plates directly on or beyond the rim were recorded as Grade 2 (Fig.1 and 2). The patients then underwent an ultrasound examination. Each patient was seated with the elbow flexed, the forearm supinated, and the shoulder in neutral position for ultrasound examination. Ultrasonography (USG) was done by a dedicated musculoskeletal radiologist to look for any attritional changes like thinning of tendon, fibrillation changes, intra-tendinous changes and complete or incomplete tears in the FPL tendon. The status of PQ repair
Copy rights@ Jayesh Anant Mhatre, et all

(1) age of 18 years upto 70 years, (2) closed distal radius fracture (at the time of presentation), (3) no nerve/vascular/tendon injuries, (4) treatment with open reduction and internal fixation with volar plating, and (5) available initial and post-reduction standard posteroanterior and lateral wrist radiographs. The exclusion criteria were (1) open fractures, (2) old

malunited fractures, (3) pathological fractures, (4) ipsilateral upper limb fractures and/or dislocation.

Demographic information was recorded at the time of the original injury included age, sex, fracture side, mechanism of injury, fracture classification, time from injury to surgery, operative approach, type of plate, fracture reduction status, plate position, repair of pronator quadratus, and timing of plate removal. The fractures were classified using the OTA fracture classification system (type A, B, and C). Operative approaches included the modified Henry approach. Volar tilt, radial tilt, radial height, and ulnar variance were measured to determine the status of fracture reduction. We measured the Soong grade for each patient according to the methods described by Soong et al.

\begin{tabular}{|l|l|}
\hline $\begin{array}{l}\text { Fracture } \\
\text { Type }\end{array}$ & $\begin{array}{l}\text { Number } \\
\text { patients }\end{array}$ \\
\hline$A 2$ & 9 \\
\hline$B 1$ & 14 \\
\hline$B 2$ & 11 \\
\hline$C 1$ & 6 \\
\hline$C 2$ & 5 \\
\hline Total & 45 \\
\hline
\end{tabular}

was also noted. The atrophic changes in FPL tendons on the operated side was detected by measuring their thickness at the level of volar lip of distal end of radius and comparing them with the contralateral side. Attritional changes were defined by the presence of thinning of the tendon, fibrillation changes, focal changes within the tendon substance or rupture of the FPL tendon. Usage of high frequency transducer ensured us in identifying the millimetric difference in the thicknesses of the tendons.

\section{Results}

There were 45 patients with a minimum of one year follow up following volar plating for distal radius fracture with PQ repair included in the study. There were 25 male and 20 female patients, with a mean age of 46.50 years (range 20-71 years). 30 patients had right wrist involvement while 15 had injury on the left wrist. 35 patients were right hand dominant and 1o were left hand dominant. Soong's criteria for plate position is shown in Fig. 1 and 2. As per this criteria, 28 patients belonged to grade 0 (22 extraarticular fractures, 6 partial -articular fractures), 10 patients belonged to grade 1 (3 extra-articular fractures, 6 partial articular fractures, one complete articular fracture) and seven patients belonged to grade 2 ( 2 partial-articular fractures, 5 complete articular fractures).

\begin{tabular}{|l|l|l|l|}
$\begin{array}{l}\text { Soong's grading of plate } \\
\text { position }\end{array}$ & Number of patients $(\mathbf{n}=\mathbf{4 5})$ & FPL attrition & FPL rupture \\
\hline Grade 0 & 28 & 0 & 0 \\
\hline Grade 1 & 10 & 3 & 0 \\
\hline Grade 2 & 7 & 7 & 0 \\
\hline
\end{tabular}




\begin{tabular}{|l|l|}
\hline USG findings & Percentage of patients with positive findings (n=10) \\
\hline Thinning of tendon & $40 \%$ \\
\hline Fibrillation changes & $60 \%$ \\
\hline Intra-tendon changes & $30 \%$ \\
\hline Partial tear & $20 \%$ \\
\hline Complete tear & 0 \\
\hline
\end{tabular}
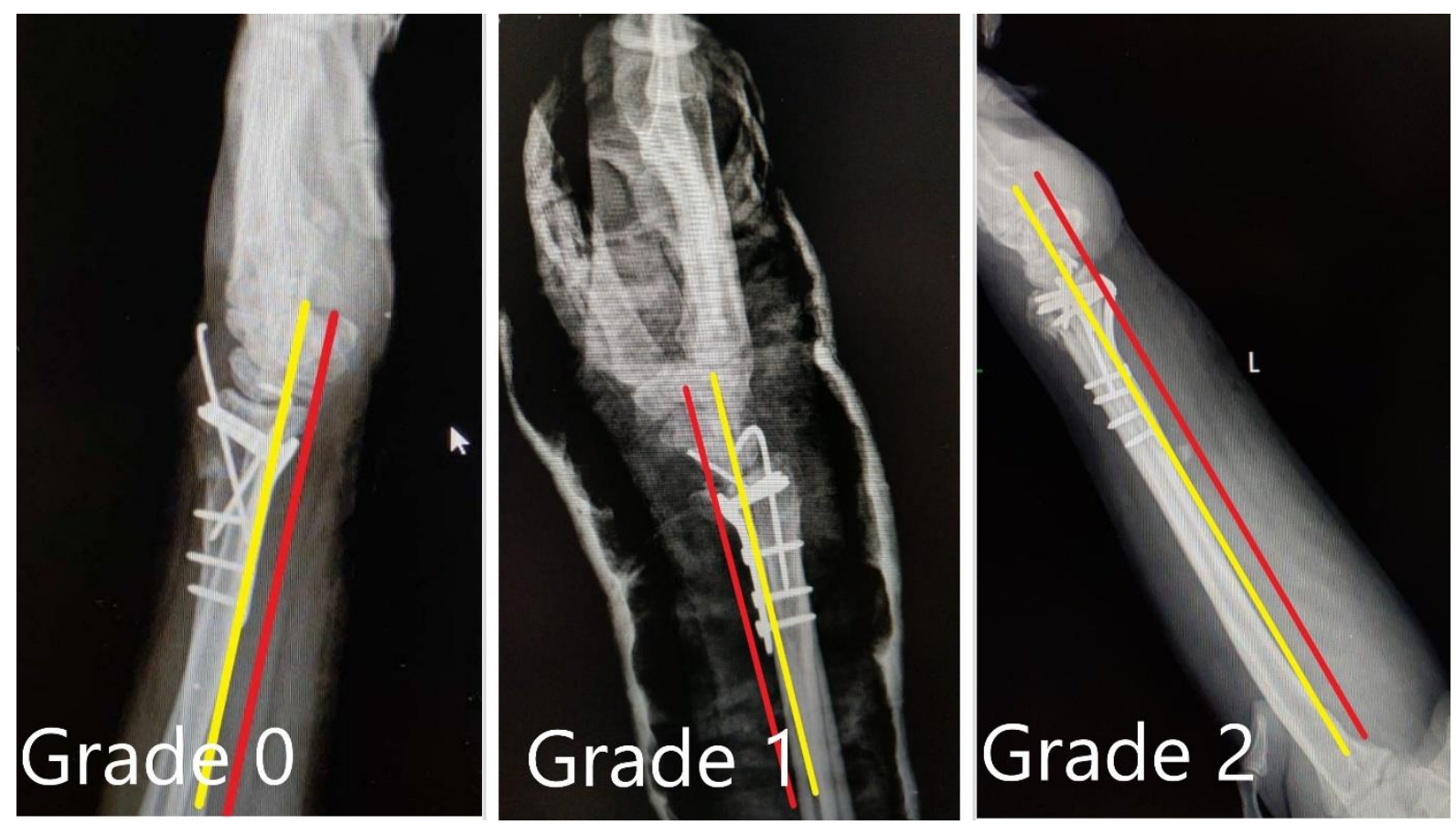

Above Figure 1 and Below Figure 2: Showing the grades of plating as per Soong's criteria. "Critical line" depicted by red colour line is drawn tangential to the most volar extent of the volar rim, parallel to the volar cortical bone of the radial shaft. Yellow line depicts the volar cortex of the radius shaft

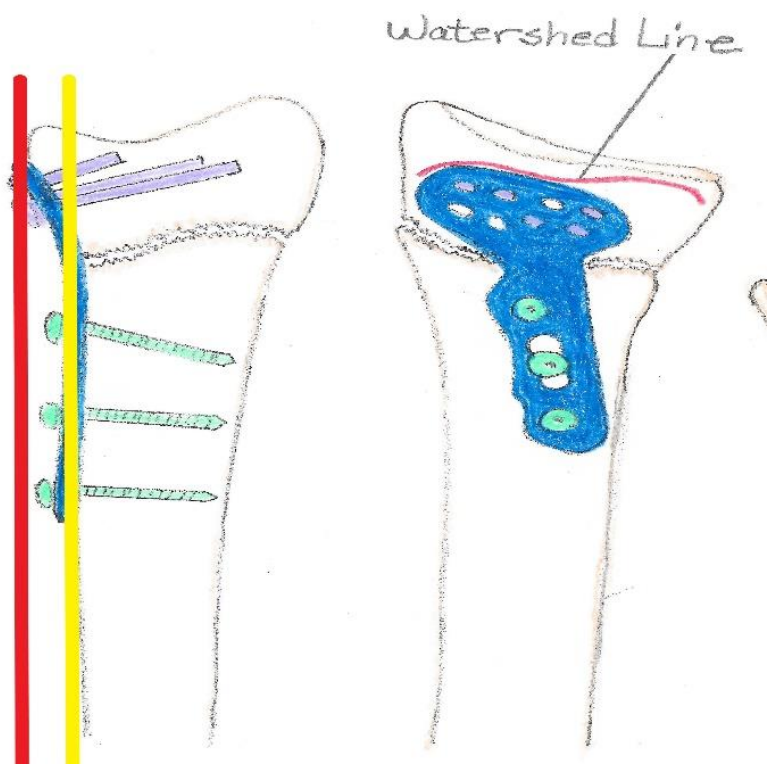


A
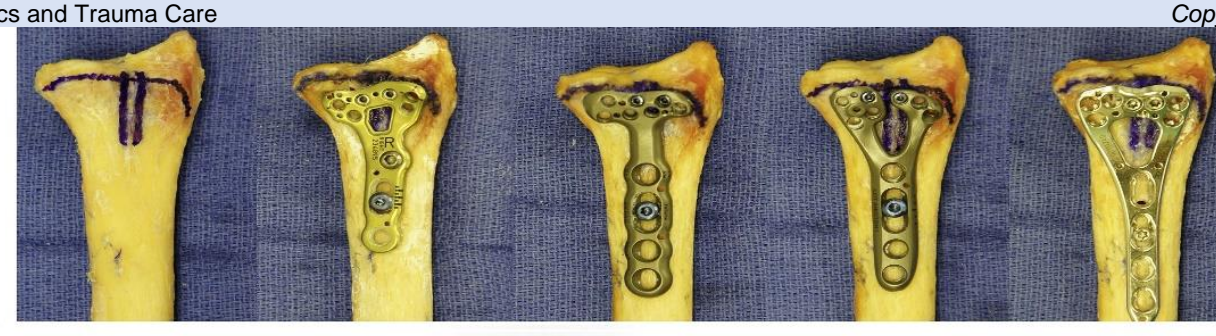

Copyrights@ Jayesh Anant Mhatre, et all
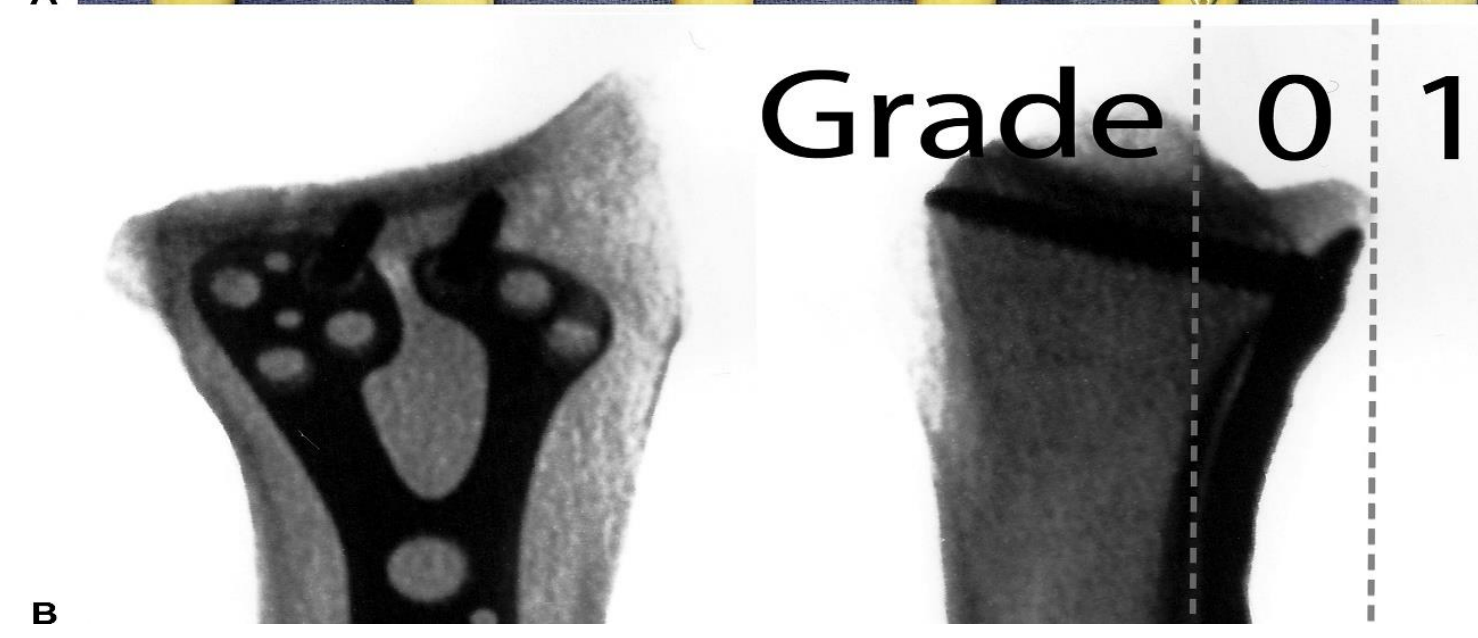

\section{Discussion}

Since its inception in 2000, volar fixed-angle fixation method has provided an effective alternative for the management of dorsal and volar fractures, it is used because fixed-angle plates eliminate the need to place the implant on the unstable side of the fracture; therefore, the more physiologic and less damaging to the soft tissue, volar approach can be used to treat the majority of fractures $[14,15]$. This approach is less damaging to the tendons as there is more space available on the volar aspect of the radius. Flexor tendons are located away from the volar surface of the radius, and the extensor tendons run directly on the dorsal surface of the bone. The volar approach allows the use of a thicker, stronger profile of the implant to better resist the loads applied during functional rehabilitation. Furthermore, modifications of volar fixed-angle fixation were based on insights into the anatomy of the radius, biomechanics, and blood supply [16, 17]. Until recently, volar reduction and internal fixation of dorsally displaced distal radius fractures was avoided as it was not believed possible. Initial attempts to achieve volar fixation of dorsal fractures were successful, leading to the extended flexor carpi radialis (FCR) volar approach that allows volar management of complex dorsally displaced distal radius fractures or their malunions [18]. The most fascinating anatomic feature of the volar aspect of the distal radius is the lack of flexor tendon-bone intimacy. Implant fixation on the volar aspect of the distal radius is also beneficial because its surface, except at the very distal margin, is flat in the transverse plane. This feature allows the accurate restoration of rotational alignment. The volar radius also presents a concave profile in the sagittal plane (the pronator fossa). This feature is limited distally by a ridge called the watershed line and allows the application of implants of substantial profile. The gliding surface of the flexor tendons should not come in contact with the plate as long as the implant is nested in the pronator fossa, does not cross its distal boundary, or project above it (Fig 1 and 2). The watershed line used as a surgical landmark because it is easily palpable as a bony prominence through the fibrous tissue that covers it, especially over the most ulnar aspect (volar rim of lunate fossa) where it is very close $(2 \mathrm{~mm})$ to the joint line. The radial aspect of the watershed line is proximal $(10-15 \mathrm{~mm})$ to the joint line as it courses along the base of the styloid process $[18,19]$.
The volar wrist capsule and ligaments insert distal to the watershed line, and the most distal edge of the pronator quadratus muscle is located several millimetres proximal [19]. Volar exposure of dorsal fractures is enhanced by releasing the radial septum (distal FCR tendon sheath, intermuscular septum, first extensor compartment, and brachioradialis). Distal release of the dorsal and volar aspects of the FCR sheath, usually distal to the superficial radial artery and scaphoid tuberosity, locates the fracture site in a more central position on the surgical approach and greatly facilitates reduction. The sheath of the first dorsal compartment must be opened on its proximal aspect to retract the abductor pollicis longus (APL) and identify the insertion of the brachioradialis into the radial styloid. Releasing this tendon eliminates the major deforming force on the radial column. A step cut tenotomy facilitates the tendon's subsequent repair and create an anchoring point for suturing the pronator quadratus muscle over the plate. Mobilizing the proximal radial fragment into pronation provides the exposure necessary to access the dorsal and articular aspects of the fracture. Exposure through the fracture plane (intrafocal exposure) allows easy debridement of fracture hematoma or interposed callus and allows reduction of complex dorsally displaced distal radius fractures. Direct observation of the reduced surface is not possible through a volar approach [19]. Assessment of fracture reduction must be achieved with fluoroscopy. Perfusion of the distal fragment occurs mainly through a dorsal vascular retinaculum that remains undisturbed during a volar approach. Perfusion to the proximal fragment occurs through branches of the anterior interosseous artery that lay on the interosseous membrane and must be protected. All main articular fracture fragments are stabilized by volar fixed-angle fixation. Posteromedial (dorsoulnar) fragments are fixed by the most ulnar pegs on the plate's proximal row, anteromedial fragments by the volar buttressing surface and the ulnar pegs on the distal row, and radial styloid fragments by the most radial pegs on both rows. Another indication for volar fixed-angle plating is the correction of established deformity. Changes in the osseous architecture of dorsal malunited fractures affect the mechanics of the radiocarpal joint, the distal radioulnar joint (DRUJ), and the forearm axis. Several investigators have advocated early surgical management of this problem to prevent degenerative changes and reduce rehabilitation time. 
J. Clinical Orthopedics and Trauma Care

The clinical importance of an adequate reduction has been stressed, and laboratory studies have shown that optimal restoration of normal volar tilt of the distal radius is crucial to prevent increased contact forces in the radiocarpal and radioulnar joints. Biomechanical studies comparing volar fixed-angle fixation plates with conventional dorsal implants report volar fixed-angle fixation plates are stronger.

Rupture or attrition of flexor tendon has been noted after volar plate fixation for distal radius fractures. Soong et al. graded the plate position on lateral radiographs and found that Soong grade 2, which is prominence of the plate above the critical line was associated with a higher risk of tendon rupture due to repeated friction of the tendon over the prominent plate. Nanno et al., using the dynamic ultrasound did the evaluation of the FPL tendon in 25 patients following volar plating of distal radius fracture evaluated the dynamic FPL movement 1 month before the plate removal and 1 month after the plate removal [20]. In their study, they showed that dynamic USG can be very useful detecting early tendon attrition of FPL by identifying the friction between the FPL tendon and plate margin. Similarly, Tanaka et al. evaluated 40 patients following distal radius volar plate fixation with mean follow up of 12 months with ultrasonic Doppler study and established different wave forms and their association with tendon attrition. They concluded that the presence of a spiked waveform would be more likely to have FPL tendon attrition [21]. However Lutsk et al. found that most of the patients who needed to undergo plate removal had Soong grade 1 prominence which theoretically had lesser possibility of tendon attrition due to proper placement of plate. They concluded that Soong grading was not correlated with the need for plate removal, even though it is recommended by many hand surgeons to prevent FPL tendon rupture in patients suspected to be at risk [22]. In our study we have noticed that all patients with grade 2 Soong had associated FPL attrition with or without PQ atrophy and two patients had partial FPL rupture, they were managed with implant removal and further physiotherapy was started to restore the function and strength. Even though it is desirable to use the volar locked compression plate in grade 0 or grade 1 position, the placement at times is determined by the fracture pattern as juxta-articular fractures may require a very distal plate placement. Dedicated rim plates or hook plates may not be available always and are more expensive. It can also occur due to placement of the plate very distal making the plate proud leading to tendon attrition. Hence, the fracture patterns may not always correlate with the position of plate. Repairing the pronator quadratus theoretically protects the flexor tendons against the volar plate and sharp edges of the screw heads and serves as a dynamic stabilizer of the distal radioulnar joint. However, PQ repair may not be optimal at all times. The repair itself might not always reach up to the distal most edge of the plate $[23,24]$. In high energy fractures, the PQ is often seen damaged badly and the repair becomes difficult in these cases owing to friability of the torn muscle fibres $[25,26]$. In our study, all patients had undergone distal radius volar plate fixation. At one year follow up, 28 patients out of 45 patients had no FPL atrophy and 10 patients had positive findings on usg in spectrum of thinning of tendon, fibrillation changes, intra-tendinous changes and complete or incomplete tears in the FPL tendon and clinically 7 patients had symptomatic tenosynovitis (swelling and pain), no patient had complete tear and the two patients with partial tear on one year follow up had radiological sings of union and thus were managed with implant removal and then later physiotherapy was started, strength improved and symptoms subsided in 1 month post second surgery.

\section{Conclusion:}

In our study, all patients had undergone open reduction and internal fixation with volar plating for distal radius fracture. At one year follow
Copy rights@ Jayesh Anant Mhatre, et all

up, all patients even though showed intact FPL, 10 patients out of 45 patients had some of the FPL changes on USG. We did have significant relation between the plate position and FPL atrophy, leading to implant removal in 20 percent of the total symptomatic patients $(n=10)$ at one year duration and hence meticulous placement of the plate becomes important for reducing attrition of the tendon post-surgery . Based on our results we recommend that if the plate has to be positioned very distally then the patients are to be followed up regularly with a dynamic USG examination and any early signs of FPL attrition should be noted. Early implant removal can be advocated in these patients once the fracture shows union to prevent tendon rupture. From our study we conclude that the plate position has greater influence on FPL tendon following distal radius fracture fixation.

\section{Funding: nil}

\section{Conflict of interest: nil}

Informed consent Written informed consent was obtained from the patient (s) for their anonymized information to be published in this article along with their surgical consent.

\section{References:}

1. Rick, T., \& Asif, M. I. (2013). Prospective evaluation of pronator quadratus repair following volar plate fixation of distal radius fractures. Journal of Hand Surgery (American Volume), $38,1678-1684$.

2. Marjolein, A. M. M., Monique, M. J. W., Fernande, J. M. E., Niels, W. L. S., \& Carel, G. (2017). Repair of the pronator quadratus after volar plate fixation in distal radius fractures: a systematic review. Strategies in Trauma and Limb Reconstruction, 17(12), 181-188.

3. Alison, K., Morgan, S., Joseph, J. S., et al. (2013). Volar plate position and flexor tendon rupture following distal radius fracture fixation. Journal of Hand Surgery (American Volume), 38, 1091-1096.

4. Protopsaltis, T. S., \& Ruch, D. S. (2008). Volar approach to distal radius fractures. Journal of Hand Surgery (American Volume), 33, 958-965.

5. ChirpazCerbat, J. M., Ruatti, S., Houillon, C., \& Ionescu, S. (2008). Dorsally displaced distal radius fractures treated by fxedangle volar plating: grip and pronosupination strength recovery. A prospective study. Orthopaedics \& Traumatology Surgery \& Research, 97, 465-470.

6. Mehdi, N. A., Margaret, P., \& Christine, A. (2009). Flexor tendon problems after volar plate fixation of distal radius fracture. Hand, 4, 406-409.

7. Berglund, L. M., \& Messer, T. M. (2009). Complications of volar plate fixation for managing distal radius fractures. Journal of American Academy of Orthopaedic Surgeons, 17, 369377.Stuart, P. R. (1996). Pronator quadratus revisited. Journal of Hand Surgery (European Volume), 21, 714-722.

8. Seigerman D, Lutsky K, and Fletcher D, et al. Complications in the management of distal radius fractures: how do we avoid them? Curr Rev Musculoskelet Med 2019; 12: 204-212.

9. Soong M, Earp BE, Bishop G, et al. Volar locking plate implant prominence and flexor tendon rupture. J Bone Joint Surg Am 2011; 93: 328-335.

10. White BD, Nydick JA, Karsky D, et al. Incidence and clinical outcomes of tendon rupture following distal radius fracture. $\mathrm{J}$ Hand Surg Am 2012; 37: 2035-2040. 
11. Limthongthang R, Bachoura A, Jacoby SM, et al. Distal radius volar locking plate design and associated vulnerability of the flexor pollicis longus. J Hand Surg Am 2014; 39: 852-860.

12. Goren $Y$, Sauerbier $M$ and Arsalan-Werner $€$ A. Impact of Soong grading on flexor tendon ruptures following palmar plating for distal radial fractures. J Hand Surg Eur Vol 2020; 45: 348-353.

13. Cross AW and Schmidt CC. Flexor tendon injuries following locked volar plating of distal radius fractures. J Hand Surg 2008; 33: 164-167.

14. Lifchez SD. Flexor pollicis longus tendon rupture after volar plating of a distal radius fracture. Plast Reconstr Surg 2010; 125: 21e-23e.

15. Adham MN, Porembski $M$ and Adham C. Flexor tendon problems after volar plate fixation of distal radius fractures. Hand (N Y) 2009; 4: 406-409.

16. Asadollahi $S$ and Keith PP. Flexor tendon injuries following plate fixation of distal radius fractures: a systematic review of the literature. J Orthop Traumatol 2013; 14: 227-234.

1. 17. Fernandez DL. Distal radius fracture: the rationale of a classification. Chir Main. 2001; 20:411-425.

17. Fernandez DL. Fractures of the distal radius: operative treatment. Instr Course Lect. 1993; 42:73-88.
Copy rights@ Jayesh Anant Mhatre, et all

18. Fernandez DL, Jupiter JB. Fractures of the Distal Radius: A Practical Approach to Management. 2nd Ed. New York: SpringerVerlag; 2002.

19. Fitoussi F, Ip WY, Chow SP. Treatment of displaced intraarticular fractures of the distal end of the radius with plates. $\mathrm{J}$ Bone Joint Surg. 1997; 79:1303-1312.

20. Georgoulis A, Lais E, Bernard M, Hertel P. [Volar plate osteosynthesis in typical and atypical distal radius fractures] Aktuelle Traumatol. 1992; 22:9-14.

21. Gesensway D, Putnam MD, Mente PL, Lewis JL. Design and biomechanics of a plate for the distal radius. J Hand Surg. 1995; 20: 1021-1027. [Am]

22. Gray H. Gray's Anatomy. 37th Ed. New York: Churchill Livingstone; 1989.

23. Hara T, Horii E, An KN, Cooney WP, Linscheid RL, Chao EY. Force distribution across wrist joint: application of pressuresensitive conductive rubber. J Hand Surg. 1992; 17:339-347. [Am]

24. Hastings H, Leibovic SJ. Indications and techniques of open reduction. Internal fixation of distal radius fractures. Orthop Clin North Am. 1993; 24:309-326.

25. Heim D. [Plate osteosynthesis of distal radius fractures-incidence, indications, and results] Swiss Surg. 2000; 6:304314.
This work is licensed under Creative Commons Attribution 4.0 License
Ready to submit your research? Choose Auctores and benefit from:

$>$ fast, convenient online submission

$>$ rigorous peer review by experienced research in your field

$>$ rapid publication on acceptance

$>$ authors retain copyrights

$>$ unique DOI for all articles

$>$ immediate, unrestricted online access

At Auctores, research is always in progress.

Learn more https://auctoresonline.org/journals/journal-of-thoracic-disease-andcardiothoracic-surgery 